\title{
Impact of fish oil enriched total parenteral nutrition on DNA synthesis, cytokine release and receptor expression by lymphocytes in the postoperative period
}

\author{
P. Schauder ${ }^{1 *}$, U. Röhn ${ }^{1}$, G. Schäfer ${ }^{1}$, G. Korff ${ }^{2}$ and H.-D. Schenk ${ }^{2}$ \\ ${ }^{1}$ Department of Medicine, Division of Gastroenterology and Endocrinology, University of Göttingen, \\ Robert-Koch-Strasse 40, D37075 Göttingen, Germany \\ ${ }^{2}$ Department of Anaesthesiology, Protestant Hospital, Göttingen-Weende, Germany
}

\begin{abstract}
A prospective randomized study on sixty patients was conducted to investigate the effects of a fish oil containing total parenteral nutrition (TPN) regimen in the postoperative period on lymphocyte subset distribution, proliferation, cytokine production and interleukin-2 receptor (IL-2R) expression. Patients who underwent large bowel surgery were divided into three groups. Nineteen patients received TPN with fish oil $(0 \cdot 2 \mathrm{~g} / \mathrm{kg}$ body weight per day) plus soybean oil $(1.0 \mathrm{~g} / \mathrm{kg}$ per day), twenty patients received soybean oil $(1.2 \mathrm{~g} / \mathrm{kg}$ per day), and twenty-one patients who were on a fat-free regimen served as the control group. Natural killer (NK) cells, total, B-, T-, $\mathrm{T}_{4^{-}}, \mathrm{T}_{8}$-lymphocytes, proliferation of lymphocytes, in vitro production of IL-2, IFN- $\gamma$, TNF- $\alpha$, and IL-2R expression were measured. Fish oil administration did not affect subset distribution and proliferation of lymphocytes. Production of interleukin-2 (IL-2), interferon $\gamma$ (IFN- $\gamma$ ) and tumor necrosis factor $\alpha(\mathrm{TNF}-\alpha)$ was augmented, and IL-2R expression less enhanced compared with the controls. It is concluded that administration of $0.2 \mathrm{~g} / \mathrm{kg}$ per day fish oil after a moderate surgical stress is not immunosuppressive, but enhances the production of IFN- $\gamma$, TNF- $\alpha$ and possibly IL-2.
\end{abstract}

\section{Parenteral nutrition: Fish oil: Cellular immunity}

\section{Introduction}

Oral ingestion of long-chain polyunsaturated fatty acids from the $n-3$ family may exert metabolic effects of potential interest for the prevention and therapy of certain diseases. Some, but not all, epidemiological observations and human feeding trials have provided evidence that diets high in fatty fish may be beneficial in preventing cardiovascular disease (Sanders, 1985; Herold \& Kinsella 1986; Ascherio et al. 1995). This has been attributed primarily to eicosapentaenic acid (EPA), a long-chain n-3 polyunsaturated fatty acid. EPA is one of the major fatty acids in fish oil, but other fatty acids with variable biological activities are also present. It has been suggested that $n-3$ fatty acids may confer protection through mechanisms such as affecting platelet function and platelet-endothelial interactions (Sanders \& Roshanai 1983). In non-human primates dietary fish oil has been observed to interrupt vascular thrombus formation (Harker et al. 1993). This may be relevant in surgical patients.
To fully appreciate the potential therapeutic value of fish oil, its other effects have to be considered, including those on the immune system. A study on six normal volunteers revealed immunosuppresive properties of fish oil, including a decrease in the release of IL-2 after stimulation with mitogens (Virella et al. 1991). In an elaborate dietary trial, with an intervention period of 24 weeks, a 'high fish' diet was shown to diminish T-cell proliferation and cytokine synthesis in humans (Meydani et al. 1993). Similar observations were made in a cohort study (Endres et al. 1993). Recently a soybean emulsion enriched with EPA was shown to reduce in seven patients the stress response and stress-induced immunosuppression including lymphocyte proliferation after a severely stressful operation, i.e. after surgery for esophageal cancer (Furukawa et al. 1999).

In this study we investigated effects of a soybean oil and fish oil containing emulsion on lymphocyte subset distribution, proliferation, cytokine release and interleukin-2

\footnotetext{
Abbreviations: TPN, total parenteral nutrition; IL-2, interleukin-2; IFN- $\gamma$, interferon $\gamma$; TNF- $\alpha$, tumor necrosis factor $\alpha$; EPA, eicosapentanoic acid; PCA, perchloric acid.

* Corresponding author: Prof. Dr. med. P. Schauder, fax: +49 55 1392620, email schauder@med.uni-goettingen.de
} 
receptor (IL-2R) expression after a moderately stressful operation, i.e. after large bowel surgery.

\section{Patients, materials and methods}

\section{Patients and clinical protocol}

This prospective, randomized, double-blind protocol was approved by the Ethics Committee of the University of Göttingen. Sixty consecutive patients were enrolled into the study. Informed written consent was obtained from all patients. They underwent large bowel surgery for malignant $(n=49)$ or benign $(n=11)$ conditions (Table 1$)$. After giving informed consent, the patients were randomly assigned to one of three study groups. Exclusion criteria were diabetes mellitus, lipid disorders, serum creatinine $>2.0 \mathrm{mg} / \mathrm{dl}$, axillary temperature $>38^{\circ} \mathrm{C}$, impaired liver function and an increased risk for postoperative complications (Peter et al. 1986). Patients were fed exclusively by total parenteral nutrition (TPN) which provided $1.5 \mathrm{~g}$ amino acids $/ \mathrm{kg}$ per day and $6.0 \mathrm{~g}$ glucose $/ \mathrm{kg}$ per day on the preoperative day. Nineteen patients received TPN with soybean oil emulsion plus fish oil (Omegavenös 10\%) (group A), and twenty patients (group B) received soybean oil emulsion (Lipovenös $10 \%$ ). Twenty-one patients were on a regimen without fat (group C). All infusion regimens contained amino acids (Aminosteril KE 10\%) and Glucose (Glucosteril $40 \%$ ). The solutions were from Fresenius AG, Bad Homburg, Germany. Vitamins, electrolytes and trace elements were added as recommended (Schmitz, 1999). Administration of the solutions was by continuous infusion. Energy content in the regimens was $100 \cdot 42 \mathrm{~kJ} / \mathrm{kg}$ per day on day one after operation, and thereafter $125 \cdot 52 \mathrm{~kJ} / \mathrm{kg}$ per day (Table 2). Administration of EPA was $0.021 \mathrm{~g} / \mathrm{kg}$ per day on day 1 and $0.042 \mathrm{~g} / \mathrm{kg}$ per day on days $2-5$ after surgery. Venous blood was obtained from the vena cava between 08.00 and 08.30 prior to operation (day - 1) and on days 3 and 6 after operation.

Table 1. Patient characteristics in the study groups

\begin{tabular}{lccc}
\hline Patient characteristics & Group A & Group B & Group C \\
\hline Women $(n)$ & 7 & 8 & 14 \\
Men $(n)$ & 12 & 12 & 7 \\
Age $($ years)* & $68(2)$ & $66(2)$ & $65(2)$ \\
Height $(\mathrm{cm})^{*}$ & $169(2)$ & $167(1)$ & $166(2)$ \\
Weight $(\mathrm{kg})^{*}$ & $68(3)$ & $70(2)$ & $66(3)$ \\
Diagnosis & & & \\
Colon carcinoma & 7 & 7 & 8 \\
Sigmoid carcinoma & 2 & 3 & - \\
Rectum carcinoma & 7 & 6 & - \\
Colon adenoma & 1 & 1 & 4 \\
Sigmoid diverticulitis & 2 & 3 & 4 \\
Procedures & & & 4 \\
Right hemicolectomy & 5 & 7 & 4 \\
Left hemicolectomy & 3 & 3 & 7 \\
Sigmoid resection & 3 & 3 & 2 \\
Anterior rectum resection & 6 & 3 & - \\
Quenue's operation & 1 & 3 & \\
Polypectomy & 1 & - & \\
\hline
\end{tabular}

${ }^{*}$ Mean values (SD).

\section{Reagents}

Reagents and their sources were as follows: concanavalin A (ConA) and poke weed mitogen (PWM) (SIGMA Chemie $\mathrm{GmbH}$, Deisenhofen, Germany); Ficoll ${ }^{\mathrm{R}}$, phosphate buffered saline (PBS), medium RPMI 1640, heat inactivated dialysed fetal calf serum (FCS), glutamine, and phytohaemagglutinin (PHA) (Biochrom KG, Berlin, Germany); penicillin/streptomycin (Gibco Europe, Karlsruhe, Germany); fatty acid free bovine albumin (BSA), insulin, and transferrin (Boehringer, Mannheim, Germany); eosin red (Serva, Heidelberg, Germany); ${ }^{3} \mathrm{H}$-thymidine, and Aquasol $^{\mathrm{R}}$ (DuPont de Nemours Dreieich, Germany); formaldehyde potassium hydroxide and perchloric acid (Merck, Darmstadt, Germany); Quantikine human IL2-ELISA (Biermann, Bad Nauheim, Germany); IFN- $\gamma$ (IRMA) system (Medgenix Ratingen, FRG); anti-human CD25-PE (phycoerythrin), immunoglobin $\mathrm{G}_{2 \mathrm{a}}-\mathrm{PE}$ (Becton Dickinson Immunocytometry Systems, San Jose, CA).

\section{Laboratory analyses}

Lymphocyte subsets were analysed in whole blood by flow cytometry (FACScan, Becton Dickinson) after specific staining with monoclonal antibodies by the APAAP-method (Cordell et al. 1984), using the SimulSet 2.3 software for calculations. The following antibodies were used (Becton Dickinson, San Jose, CA): anti CD3 for T-lymphocytes, anti CD19 for B-lymphocytes, anti CD4 for T-helper cells, anti CD8 for T-suppressor cells, anti CD16 and anti CD56 for NK cells.

Lymphocytes were isolated from heparinized venous blood by Ficoll ${ }^{\mathrm{R}}$-Hypaque gradient (Boyum 1968) as previously described (Koch et al. 1990; Schröder et al. 1990). To reduce the variability of monocytes/macrophages $(10-20 \%)$ in the preparation, cells were incubated for $15 \mathrm{~min}$ at $37^{\circ} \mathrm{C}$ in RPMI 1640 containing $5 \%$ (v/v) dialysed FCS, glutamine $(2 \mathrm{mM})$, penicillin $(100 \mathrm{U} / \mathrm{ml}$, and streptomycin $(100 \mu \mathrm{g} / \mathrm{ml})$. Under these conditions monocytes/ macrophages preferentially adhered to the plastic of the tissue culture flasks. Nonadherent cells were harvested, washed in PBS, and suspended for culture. The composition of cells in the suspension was as follows: $76 \%$ T-lymphocytes, $10 \%$ NK cells, 7\% B-lymphocytes, and 5-8\% monocytes/macrophages. Lymphocytes $\left(7 \times 10^{6}\right.$ cells $\left./ 5 \mathrm{ml}\right)$ were cultured for 24 or $48 \mathrm{~h}$ in a

Table 2. Macronutrients in the postoperative parenteral nutrition regimen

\begin{tabular}{lcll}
\hline Nutrient & Study group & \multicolumn{1}{c}{ Day 1 } & \multicolumn{1}{c}{ Days 2-5 } \\
\hline Glucose & A & 3.0 & 3.0 \\
& B & 3.0 & 3.0 \\
Fat & C & 4.5 & 6.0 \\
& A & 0.5 (soybean oil) & 1.0 (soybean oil) \\
& & 0.1 (fish oil) & 0.2 (fish oil) \\
Amino acids & B & 0.6 (soybean oil) & 1.2 (soybean oil) \\
& C & - & - \\
& A & 1.5 & 1.5 \\
& B & 1.5 & 1.5 \\
\hline
\end{tabular}

Values represent $\mathrm{g} / \mathrm{kg}$ body weight per day. 


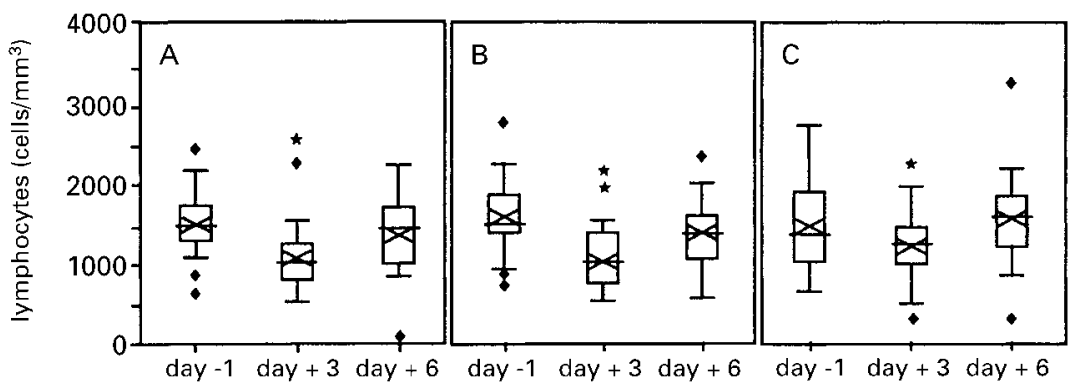

Fig. 1. The number of venous lymphocytes in patients receiving fat free, soybean oil-enriched or fish oil-enriched parenteral nutrition post-surgery. Mean values from group $\mathrm{A}, \mathrm{B}$ and $\mathrm{C}$ are shown by the cross and the medians by the horizontal line in the box. Minimal, maximal and extreme cell numbers are indicated by a rhombus. ${ }^{\star} P<0.025 ;{ }^{*} P<0.005 \mathrm{v}$. pre-operative values (day -1 ).

humidified atmosphere $\left(5 \% \mathrm{CO}_{2}\right.$ in air) in medium RPMI 1640 supplemented with $1 \%$ fatty acid free bovine albumin (w/v), glutamine $(2 \mathrm{mM})$, insulin $(10 \mu \mathrm{g} / \mathrm{ml})$, transferrin $(10 \mu \mathrm{g} / \mathrm{ml})$, penicillin $(100 \mathrm{U} / \mathrm{ml})$, and streptomycin $(100 \mu \mathrm{g} / \mathrm{ml})$.

In the experiments designed to study DNA synthesis, ConA $(10 \mu \mathrm{g} / \mathrm{ml})$ was used as mitogen. Production of interferon $\gamma$ (IFN- $\gamma$ ), interleukin-2 (IL-2) and IL-2R expression were analyzed in cells stimulated with $0.24 \mu \mathrm{g}$ $\mathrm{PHA} / \mathrm{ml}$ for $48 \mathrm{~h}$. In experiments to study tumor necrosis factor $\alpha$ (TNF- $\alpha$ ) production, $2 \cdot 0 \mu \mathrm{g}$ PWM $/ \mathrm{ml}$ was added for $24 \mathrm{~h}$. Before and after incubation cell viability was examined by eosin exclusion.

DNA synthesis was determined by measuring ${ }^{3} \mathrm{H}$-thymidine incorporation into DNA. ${ }^{3} \mathrm{H}$-thymidine $(0.2 \mu \mathrm{Ci} / \mathrm{ml})$ was added to the cultures during the final $4 \mathrm{~h}$ of a $48 \mathrm{~h}$ incubation. The labelled cells were harvested by centrifugation $(10 \mathrm{~min}$ at $250 \mathrm{~g}$ ), washed twice in PBS, and precipitated with $1.5 \mathrm{ml}$ cold $0.5 \mathrm{~N}$ perchloric acid (PCA). RNA was hydrolyzed by incubation with $0.3 \mathrm{~N} \mathrm{KOH}$ $(0.5 \mathrm{ml})$ at $37^{\circ} \mathrm{C}$ for $90 \mathrm{~min}$. After reprecipitation with $0.5 \mathrm{ml}$ $10 \%$ PCA and washing three times with $1.5 \mathrm{ml} 0.5 \mathrm{~N} \mathrm{PCA}$, the precipitate was finally resuspended in $1.5 \mathrm{ml} 0.5 \mathrm{~N}$ PCA. To hydrolyze DNA, suspensions were heated for $20 \mathrm{~min}$ at $75^{\circ} \mathrm{C}$. Aliquots of the solubilized material were transferred to scintillation vials, mixed with $5 \mathrm{ml}$ Aquasol $^{\mathrm{R}}$, and measured for radioactivity in a Mark III liquid scintillation spectrometer (Searle, Des Plaines, IL).
Cytokine concentrations in culture supernatants were measured using commercially available assay kits based on the ELISA (IL-2, TNF- $\alpha$ ) or the IRMA (IFN- $\gamma$ ) technique. None of the assays showed cross-reactivity with other cytokines. Minimum detectable doses were as follows: IL-2, $6 \cdot 0 \mathrm{pg} / \mathrm{ml}$; IFN- $\gamma, 0 \cdot 2 \mathrm{IU} / \mathrm{ml} ; \mathrm{TNF}-\alpha 60-100 \mathrm{pg} / \mathrm{ml}$. Coefficients of variations for intra-assay precision were as follows: TNF- $\alpha$ 5-8\%, IL-2 4-7\%, IFN- $\gamma 2-3 \%$. Those for inter-assay precision were as follows: IL-2 6-9\%, IFN- $\gamma 7-10 \%$, TNF- $\alpha$ 8-10\%. After incubations aliquots from supernatants were frozen at $-20^{\circ} \mathrm{C}$ pending assay. Samples had to be diluted with culture medium 1:10 (v/v) when assaying IFN- $\gamma$. Readings of optical densities were made on a MR 5000 microplate reader (Dynatech Laboratories, Guernsey, Channel Islands, UK). ${ }^{125}$-Iodine was counted in a 1277 Automatic Gamma Counter (LKB Wallac, Turku, Finland).

IL-2 receptor expression was determined using the phycoerythrin (PE)-conjugated monoclonal antibody antihuman CD25. After a $48 \mathrm{~h}$ culture period, $5 \times 10^{5}$ lymphocytes of each culture flask were incubated for 30 min with $10 \mu \mathrm{l}$ antibody solution. Thereafter, cells were washed twice using PBS containing $2 \%(\mathrm{v} / \mathrm{v})$ FCS and finally resuspended in $1 \%$ formaldehyde in PBS. Cells incubated with aliquots of the Simultest ${ }^{\mathrm{TM}}$ control mixture (containing $\mathrm{IgG}_{2 \mathrm{a}}-\mathrm{PE}$ ) were used to correct for nonspecific staining. Analyses were performed on a FACScan flow cytometer (Becton-Dickinson). Mean peak channels (MPC)

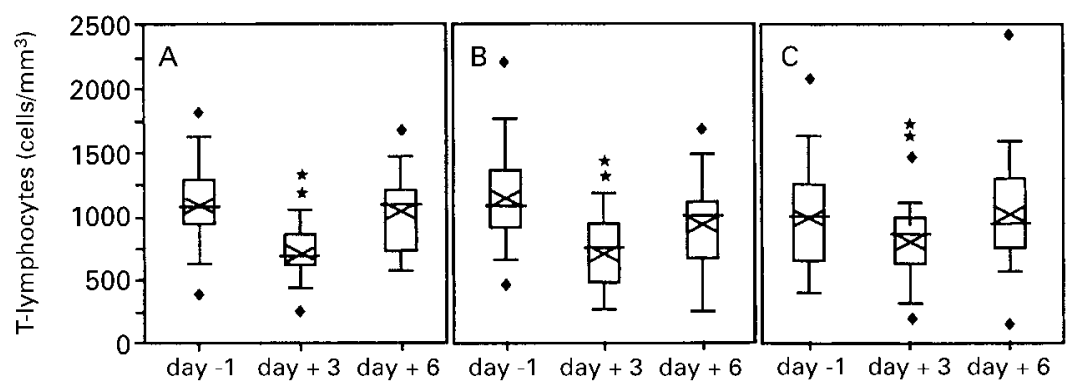

Fig. 2. The number of venous T-lymphocytes in patients receiving fat free, soybean oil-enriched or fish oil-enriched parenteral nutrition post-surgery. Mean values from group $\mathrm{A}, \mathrm{B}$ and $\mathrm{C}$ are shown by the cross and the medians by the horizontal line in the box. Minimal, maximal and extreme cell numbers are indicated by a rhombus. ${ }^{\star} P<0.025 ;{ }^{* *} P<0.005$ 


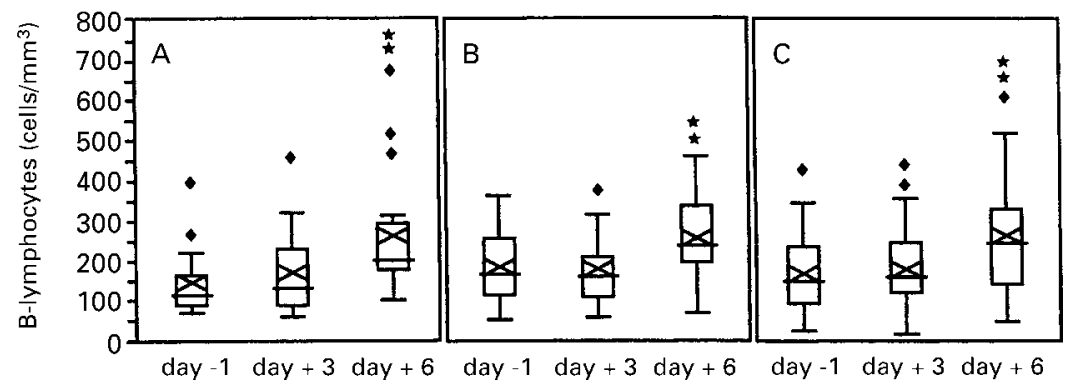

Fig. 3. The number of venous B-lymphocytes in patients receiving fat free, soybean oil-enriched or fish oil-enriched parenteral nutrition post-surgery.Mean values from group $\mathrm{A}, \mathrm{B}$ and $\mathrm{C}$ are shown by the cross and the medians by the horizontal line in the box. Minimal, maximal and extreme cell numbers are indicated by a rhombus. ${ }^{*} P<0.025$.

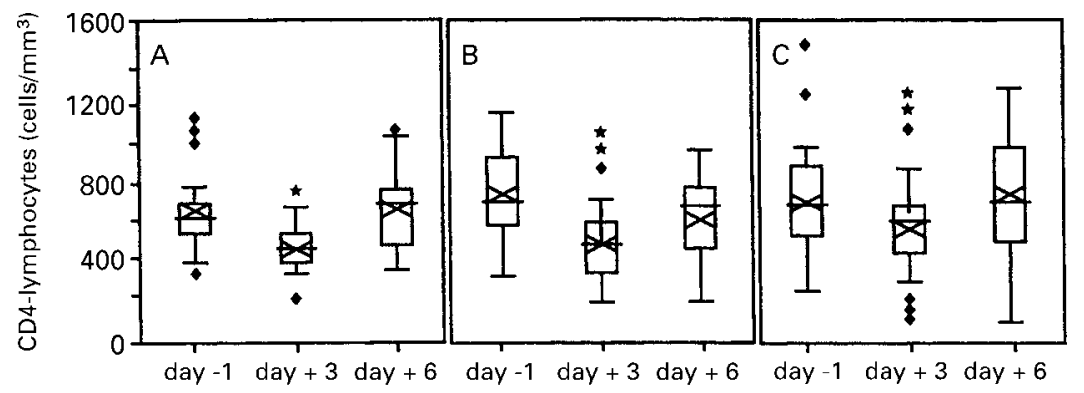

Fig. 4. The number of venous $\mathrm{CD}_{4}$-lymphocytes in patients receiving fat free, soybean oil-enriched or fish oil-enriched parenteral nutrition post-surgery. Mean values from group $\mathrm{A}, \mathrm{B}$ and $\mathrm{C}$ are shown by the cross and the medians by the horizontal line in the box. Minimal, maximal and extreme cell numbers are indicated by a rhombus. ${ }^{\star} P<0.025 ;{ }^{* \star} P<0.005$.

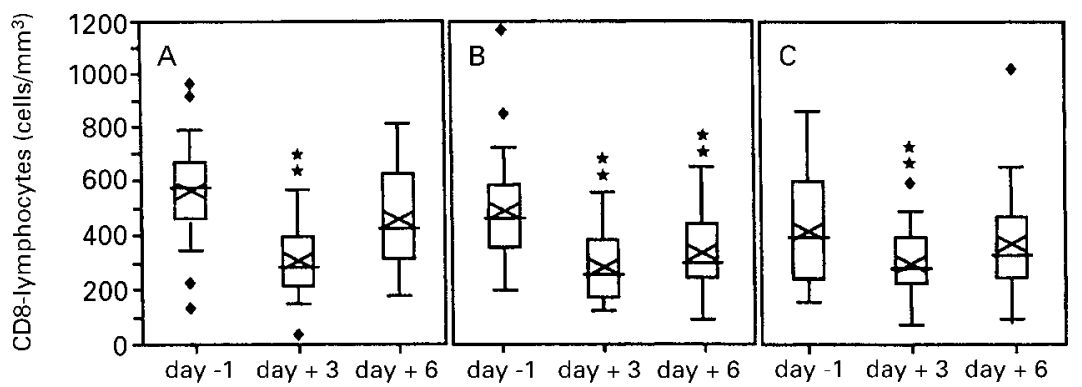

Fig. 5. The number of venous $C_{8}$-lymphocytes in patients receiving fat free, soybean oil-enriched or fish oil-enriched parenteral nutrition post-surgery. Mean values from group $\mathrm{A}, \mathrm{B}$ and $\mathrm{C}$ are shown by the cross and the medians by the horizontal line in the box. Minimal, maximal and extreme cell numbers are indicated by a rhombus. ${ }^{*} P<0.025 ;{ }^{* \star} P<0.005$.

found with $\operatorname{IgG}_{2 \mathrm{a}}-\mathrm{PE}$ were subtracted from those found with anti-CD25-PE.

\section{Statistics}

Logarithmic transformation of the DNA-synthesis data rendered them parametric, and statistical analysis used the PSC 3.03 program (Top-Soft, Hannover, Germany). Data obtained before and after TPN with treatment groups were analysed using the paired $t$-test. A relatively small change in the logarithmic data in Table 4 represents a considerable change in the untransformed data. Results were considered statistically significant, if $P<0 \cdot 025$. Data are expressed as mean values (SD) in the tables and as box plots in the figures.

\section{Results}

The clinical details of all the patients studied are shown in Table 1. There were no statistical differences among the 


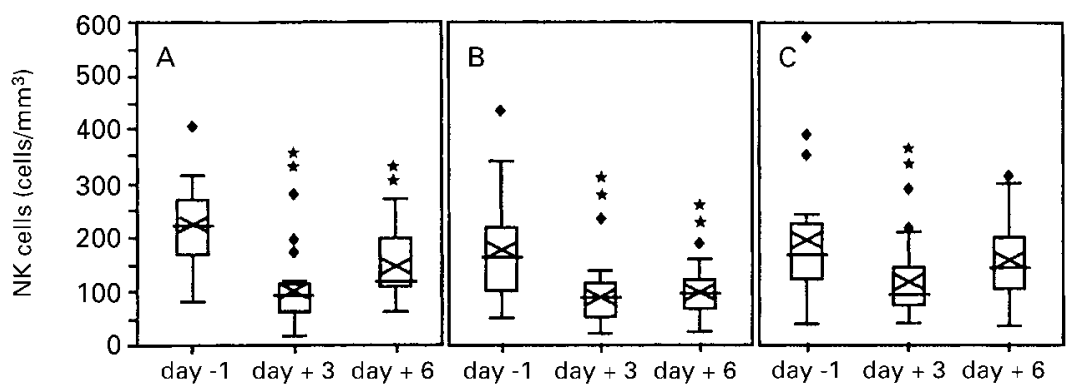

Fig. 6. The number of venous NK-cells in patients receiving fat free, soybean oilenriched or fish oil-enriched parenteral nutrition post-surgery. Mean values from group $\mathrm{A}, \mathrm{B}$ and $\mathrm{C}$ are shown by the cross, and the medians by the horizontal line in the box. Minimal, maximal and extreme cell numbers are indicated by a rhombus. ${ }^{*} P<0.025$.

Table 3. The $C D_{4} / C D_{8}$ ratio in patients receving fat free, soybean oil - enriched or fish oil-enriched parenteral nutrition post-surgery

\begin{tabular}{lccc}
\hline & \multicolumn{3}{c}{$\mathrm{CD}_{4}-\mathrm{CD}_{8}$ ratio } \\
\cline { 2 - 4 } Day & Group A $(n 18)$ & Group B $(n 20)$ & Group C $(n 21)$ \\
\hline-1 & $1.4(0.2)$ & $1.7(0.1)$ & $1.9(0.2)$ \\
+3 & $1.6(0.1)$ & $1.8(0.1)$ & $2.2(0.3)$ \\
+6 & $1.8(0.3)^{\star \star}$ & $2.0(0.1)^{\star}$ & $2.2(0.3)$ \\
\hline
\end{tabular}

Mean values (SD); ${ }^{\star} P<0.025 ;{ }^{* \star} P<0.005 \mathrm{v}$. pre-operative value (day -1 ).

Table 4. DNA-synthesis by lymphocytes in patients receiving fat free, soybean Oil-enriched or fish oil-enriched parenteral nutrition post-surgery

\begin{tabular}{|c|c|c|c|c|}
\hline DNA synthesis & Day & $\begin{array}{c}\text { Group A } \\
(n 15)\end{array}$ & $\begin{array}{c}\text { Group B } \\
(n 17)\end{array}$ & $\begin{array}{c}\text { Group C } \\
(n 16)\end{array}$ \\
\hline \multirow[t]{3}{*}{ Unstimulated } & -1 & $2.15(0.16)$ & $2.21(0.11)$ & $2.20(0.14)$ \\
\hline & +3 & $2.53(0.14)^{\star *}$ & $2.73(0.14)^{\star *}$ & $2.59(0.13)^{\star}$ \\
\hline & +6 & $3.21(0.15)^{\star \star}$ & $3.06(0.11)^{\star \star}$ & $2.92(0.10)^{\star \star}$ \\
\hline \multirow[t]{3}{*}{ Stimulated } & -1 & $2.29(0.15)$ & $2.38(0.10)$ & $2.37(0.11)$ \\
\hline & +3 & $2.67(0.12)^{\star *}$ & $2.81(0.10)^{\star \star *}$ & $2.74(0.12)^{\star *}$ \\
\hline & +6 & $3.14(0.13)^{\star \star}$ & $2.99(0.12)^{\star *}$ & $2.91(0.10)^{\star \star}$ \\
\hline
\end{tabular}

Values represent $\log \mathrm{cpm} / \mathrm{I} \times 10^{6}$ cells per $4 \mathrm{~h}$ [mean (SD)]. Stimulation was with ConA. ${ }^{*} P<0.025 ;{ }^{\star *} P<0.005$ v. pre-operative values (day-1).

Table 5. Cytokine production by lymphocytes in patients receving fat free, soybean oil-enriched or fish oil-enriched parenteral nutrition post-surgery

\begin{tabular}{lcccc}
\hline Cytokine & Day & $\begin{array}{c}\text { Group A } \\
(n \text { 18) }\end{array}$ & $\begin{array}{c}\text { Group B } \\
(n \text { 18) }\end{array}$ & $\begin{array}{c}\text { Group C } \\
(n \text { 20) }\end{array}$ \\
\hline IL-2 & -1 & $495(70)$ & $959(138)^{a}$ & $816(76)^{\mathrm{a}}$ \\
& +3 & $689(134)$ & $803(98)$ & $800(76)$ \\
IFN- $\gamma$ & +6 & $847(140)^{\star}$ & $895(112)$ & $726(83)$ \\
& -1 & $127(18)$ & $170(19)$ & $147(14)$ \\
& +3 & $123(16)$ & $130(20)^{\star}$ & $101(12)^{\star *}$ \\
TNF- $\alpha$ & +6 & $155(37)$ & $144(26)$ & $82(10)^{\star *}$ \\
& -1 & $9 \cdot 1(1.4)$ & $10 \cdot 8(1.4)$ & $11(1.5)$ \\
& +3 & $14.1(3.4)$ & $14.6(1.8)$ & $12.7(1.6)$ \\
& +6 & $14.4(2 \cdot 1)^{\star}$ & $17.0(3.0)$ & $13.4(1.5)$ \\
\hline
\end{tabular}

Values represent $\mathrm{pg}, \mathrm{IU}$, or $\mathrm{ng} / \mathrm{I} \times 10^{6}$ cells for IL-2, IFN- $\gamma$ or TNF- $\alpha$, respectively [mean (SD)].

${ }^{*} P<0.025 ;{ }^{*} P<0.005 \mathrm{v}$. pre-operative values (day -1 ). ${ }^{\mathrm{a}} P<0.025$ compared with group $\mathrm{A}$. three groups in age, height and body weight. The ratios between men and women in groups A, B and C were 12:7, $12: 8$ and $7: 14$, and between malignant and benign disease $17: 2,17: 3$ and 17:4, respectively. The profiles of lymphocyte subset distributions are shown in Figs 1-6, and in Table 3. Total lymphocytes significantly declined in all groups on day 3, and returned towards baseline on day 6 after surgery (Fig. 1). This decline was due to a reduction in the number of T-lymphocytes (Fig. 2), whereas B-lymphocyte numbers increased in the postoperative period (Fig. 3). In all groups the number of $\mathrm{CD}_{4^{-}}$and $\mathrm{CD}_{8}$-lymphocytes declined significantly, but this decrease was more pronounced for $\mathrm{CD}_{8}$-lymphocytes (Figs 4 and 5). This resulted in an increase of the $\mathrm{CD}_{4} / \mathrm{CD}_{8}$ ratio, which reached statistical significance in groups $\mathrm{A}$ and $\mathrm{B}$ (Table 3 ). The postoperative numbers of NK cells declined significantly in all groups, compared with baseline values (Fig. 6).

Stimulated and unstimulated ${ }^{3} \mathrm{H}$-thymidine uptake before and after surgery was not significantly different in the three treatment groups. Spontaneous (basal) ${ }^{3} \mathrm{H}$-thymidine uptake by unstimulated lymphocytes was augmented significantly on days 3 and 6 after surgery. Mitogen-stimulated ${ }^{3} \mathrm{H}$-thymidine uptake was low on day 3 and absent on day 6 after surgery. None of the TPN regimens had any effect on these profiles (Table 4).

There was no significant change in supernatant IL-2 content before and after TPN with the regimens based on glucose as energy source or on glucose plus soybean oil. The IL-2 content of supernatants from PHA-activated lymphocytes was significantly augmented following 5 days of fish oil containing TPN. However, IL-2 production in the fish oil group prior to the operation was significantly lower than in the two other groups (Table 5). Production of IFN- $\gamma$ significantly declined in patients on the fat-free TPN regimen on days 3 and 6 after surgery. This was not observed in the group receiving fish oil, and only on day 3 in patients given soybean oil emulsion (Table 5). Production of TNF- $\alpha$ was significantly enhanced on day 6 after surgery in patients receiving fish oil (Table 5).

In lymphocytes from the controls (group C) an increase in IL-2R expression occurred on days 3 and 6 after operation. This was not observed in patients on the TPN regimen with soybean oil, whereas IL-2 R expression in patients receiving 
Table 6. IL-2 receptor expression by lymphocytes in patients receving fat free, soybean oil-enriched or fish oil-enriched parenteral nutrition post-surgery

\begin{tabular}{llcc}
\hline & \multicolumn{3}{c}{ IL-2 receptor positive cells (\%) } \\
\cline { 2 - 4 } Day & $\begin{array}{c}\text { Group A } \\
(n \text { 8) }\end{array}$ & $\begin{array}{c}\text { Group B } \\
(n \text { 9) }\end{array}$ & $\begin{array}{c}\text { Group C } \\
(n \text { 7) }\end{array}$ \\
\hline-1 & $27.6(2.3)$ & $32.3(2 \cdot 7)$ & $30.4(2.0)$ \\
+3 & $35.0(2.5)^{*}$ & $33.9(2 \cdot 6)$ & $36.9(2.2)^{*}$ \\
+6 & $34.5(2.3)$ & $34.7(2 \cdot 7)$ & $39.2(2.7)^{*}$ \\
\hline
\end{tabular}

Mean values (SD); ${ }^{*} P<0.025 \mathrm{v}$. pre-operative values (day -1 ).

the fish oil enriched emulsion (group A) was augmented on the third postoperative day only (Table 6).

\section{Discussion}

This investigation shows that the administration of a TPN regimen containing fish oil had few effects on aspects of cellular immunity which were not observed with regimens based on glucose only, or on glucose plus soybean oil as an energy source. As shown in Fig. 1, the total number of lymphocytes declined significantly during the postoperative period in patients receiving fish oil enriched fat emulsions, and in the two other groups. Lymphocytopenia is well established after major surgery. Stress induced by surgery enhances the release of steroids. This appears to cause redistribution of lymphocytes from the vascular compartment into lymph nodes, spleen and bone marrow. It has been shown that T-lymphocytes mainly contribute to these changes (Spey, 1972; Cox \& Ford 1982; Lennard et al. 1985; Hisatomi et al. 1989; Lindh et al. 1992). Our report is in keeping with this.

As shown in Figs 2 and 3 total lymphocytes declined because T-lymphocyte numbers decreased while B-lymphocyte numbers increased. Previous investigators described no changes or a decrease in B-lymphocyte numbers following surgery (Lennard et al. 1985; Tönnesen \& Wahlgreen 1988). The reason for these discrepancies is unclear.

There was a significant decline in $\mathrm{CD}_{4^{-}}$and $\mathrm{CD}_{8^{-}}$ lymphocyte numbers in groups A, B and C (Figs 4 and 5). A decrease in $\mathrm{CD}_{4}$-cell numbers after minor and major surgery, as well as in $\mathrm{CD}_{8}$-cells after major surgery, has been previously observed (Lennard et al. 1985; Tönnesen \& Wahlgreen 1988). Because of a more pronounced decrease in $\mathrm{CD}_{8}$-lymphocyte numbers compared with $\mathrm{CD}_{4}$-cell numbers, there was a significant augmentation in the $\mathrm{CD}_{4} /$ $\mathrm{CD}_{8}$-ratio (Table 3). NK-cell numbers declined significantly in all groups (Fig. 6). A decrease in NK-cells was previously observed after major surgery. (Tönnesen et al. 1984, 1987, 1993; Ryhänen et al. 1984; Parillo \& Fauci 1978). Thus, intravenous fish oil administration did not affect the lymphocyte subset distribution seen after a moderately stressful operation.

Data on DNA-synthesis by lymphocytes in response to lipids are conflicting (Guillou, 1993). Lipids reportedly augment (Kelly and Parker, 1979; Spieker-Polet \& Polet 1981, diminish (Mertin \& Hughes 1975; Calder et al. 1989; Calder \& Newsholme 1992) or have no effect on lymphocyte proliferation (Tizard \& Sheppard 1982). Similar effects can be exerted by single free fatty acids. Several free fatty acids are known to increase, to not affect or to decrease proliferation of lymphocytes from human subjects, depending upon their concentration in the incubation medium (Karsten et al. 1994).

Postoperative stress has been shown to impair immune functions (Slade et al. 1975; Walton, 1979; Eskola et al. 1984). It seems possible to modulate this stress response by a lipid-containing TPN regimen. Lectin-induced lymphocyte proliferation was reportedly increased in surgical patients by TPN that contained an emulsion with long-chain and medium-chain triglycerides (Sedman et al. 1991). EPA also appears to affect the immune system in postoperative patients. Administration of soybean oil supplemented with EPA reportedly partly prevented the postoperative decline of ConA and PHA-stimulated ${ }^{3} \mathrm{H}$-thymidine uptake by lymphocytes in seven patients after esophageal surgery (Furukawa et al. 1999). This is in contrast to the data shown in Table 4, which indicates that none of the fat-containing TPN regimens affected the postoperative patterns of ${ }^{3} \mathrm{H}$-thymidine uptake, and also reports that fish oil reduced lymphocyte proliferation in non-stressed (i.e. not operated) subjects (Calder, 1993; Endres et al. 1993). To explain the differences with the data from non-stressed subjects, it was suggested that the effect of EPA on immune functions in a stressed state is different from that in a non-stressed state (Furukawa et al. 1999). This can also serve as an explanation for the discrepancies with our results. Esophageal surgery is one of the most severe surgical procedures (Furukawa et al. 1999), while stress due to large bowel surgery, as in our patients, is considered to be comparatively modest. A further possible reason for differences in the results may be the amount of EPA administered per day. In the study of Furukawa et al. $1.8 \mathrm{~g} /$ day EPA was given as compared with $2.94 \mathrm{~g} /$ day EPA in this investigation, based on a body weight of $70 \mathrm{~kg}$.

Even though there was a statistically significant postoperative increase in IL-2 production in the group receiving fish oil, this augmentation may not be of biological significance because it occurred against a background of a significantly lower preoperative production rate compared with the two other groups (Table 5). Expression of the IL-2 receptor was augmented in patients on the fat-free TPN regimen 3 and 6 days after surgery. This also occurred in patients receiving fish oil, but only on day 3. IL-2R expression in patients on soybean oil remained unaffected. Less augmentation of IL-2R expression in the fish oil group compared with controls may indicate interference with some effects mediated via IL-2. However, this does not seem to pertain to lymphocyte proliferation, as suggested by data in Table 4.

In the patients on the fat free-TPN regimen postoperative IFN- $\gamma$ production was significantly diminished compared with the preoperative values. This was not observed in patients given fish oil, and only on day 3 after surgery in the patients receiving soybean oil. A postoperative increase in the production of TNF- $\alpha$ was observed with the fish oil regimen, unlike in patients on TPN without fat (Table 5).

Thus, the post-surgery pattern of lymphocyte subset distribution and proliferation of lymphocytes in patients on 
TPN containing fish oil was the same as that seen in the controls. Therefore, in moderately stressed surgical patients, fish oil at a dosage of $0 \cdot 1 \mathrm{~g} / \mathrm{kg}$ per day given for 1 day, and $0 \cdot 2 \mathrm{~g} / \mathrm{kg}$ per day for 4 days, seems not to be immunosuppressive. The possible biological significance of the apparent increase in the production rates of IL-2, IFN- $\gamma$ and TNF- $\alpha$ remains to be established.

\section{References}

Ascherio A, Rimm BE, Stampfer MJ, Givannucci EL \& Willet WC (1995) Dietary intake of marine $n-3$ fatty acids, fish intake, and the risk of coronary disease among men. New England Journal of Medicine 332, 977-982.

Boyum A (1968) Separation of lymphocytes from blood and bone marrow. Scandinavian Journal of Clinical and Laboratory Investigation 21, 51-56.

Calder PC, Bond JA \& Newsholme EA (1989) Fatty acid inhibition of concanavalin A-stimulated lymphocyte proliferation. Biochemical Society Transactions 17, 1042-1043.

Calder PC \& Newsholme EA (1992) Polyunsaturated fatty acids suppress human peripheral blood lymphocyte proliferation and interleukin 2 production. Clinical Science 82, 695-700.

Calder PC (1993) The effects of fatty acids on lymphocyte function. Brazilian Journal of Medical Research 26, 901-917.

Cordell JL, Falini B, Erber WN, Ghosh AK, Abdulaziz Z, Macdonald ST, Pulford KAF, Stein H \& Mason DY (1984) Immunoenzymatic labeling of monoclonal antibodies using immune complexes of alkaline phosphatase and monoclonal anti alkaline phosphatase (APAAP-complexes). Journal of Histochemistry and Cytochemistry 32, 219-229.

Cox JH \& Ford WL (1982) The migration of lymphocytes across specialized vascular endothelium. Prednisolone acts at several points on the recirculation pathways of lymphocytes. Cellular Immunology 66, 407-412.

Endres S, Meydani SN, Ghorbani R, Schindler R \& Dinarello CA (1993) Dietary supplementation with $n-3$ fatty acids suppresses interleukin-2 production and mononuclear cell proliferation. Journal of Leukocyte Biology 54, 599-603.

Eskola J, Salo M, Viljanen MK \& Ruuskanen O (1984) Impaired B lymphocyte function during open heart surgery. Effects of anaesthesia and surgery. British Journal of Anaesthesia 56, $333-338$.

Furukawa K, Tashiro T, Yamamori H, Tagaki K, Morishima Y, Sugiura T, Otsubo Y, Hayashi N, Itabashi T, Sano W, Toyoda W, Nitta H \& Nakajima N (1999) Effects of soybean oil emulsion and eicosapentaenoic acid on stress response and immune function after severely stressful operation. Annals of Surgery 229, 255-261.

Guillou PJ (1993) The effects of lipids on some aspects of the cellular immune responses. Proceedings of the Nutrition Society 52, 91-100.

Harker LA, Kelly AB, Hanson SR, Krupski W, Bass A, Osterud B, Fitzgerald BA, Goodnight SH \& Connor WE (1993) Interruption of vascular thrombus fromation and vascular lesion formation by dietary $n-3$ fatty acids in fish oil in nonhuman primates. Circulation 87, 1017-1029.

Herold PM \& Kinsella JE (1986) Fish oil consumption and decreased risk of cardiovascular disease: a comparison of findings from animal and human feeding trials. American Journal of Clinical Nutrition 43, 566-598.

Hisatomi K, Isomura T, Kawara T, Yamashita M, Hiran A, Yoshida H, Eriguchi N, Kosuga K \& Ohishi K (1989) Changes in lymphocyte subsets, mitogen responsiveness and interleukin-2 production after cardiac operations. Journal of Thoracic and Cardiovascular Surgery 98, 580-591.
Karsten S, Schäfer G \& Schauder P (1994) Cytokine production and DNA synthesis by human peripheral lymphocystes in response to palmitic, stearic, oleic and linoleic acid. Journal of Cellular Physiology 161, 15-22.

Kelly JP \& Parker CW (1979) Effects of arachidonic acid and other unsaturated fatty acids on mitogenesis in human lymphocytes. Journal of Immunology 122, 1556-1562.

Koch B, Schröder MT, Schäfer G \& Schauder P (1990) Comparison between transport of leucine and glutamine by peripheral human lymphocytes exposed to concanavalin A. Journal of Cellular Physiology 143, 94-99.

Lennard TWJ, Shenton BK, Borzotta A, Donnelly PK, White M, Gerrit LM, Proud G \& Taylor RMR (1985) The influence of surgical operations on components of the human immune system. British Journal of Surgery 72, 771-776.

Lindh K, Carlström J, Eklund J \& Wilking N (1992) Serum steroids and prolactin during and after major surgical trauma. Acta Anaesthesiologica Scandinavica 36, 119-124.

Mertin J \& Hughes D (1975) Specific inhibitory action of polyunsaturated fatty acids on lymphocyte transformation induced by PHA and PPD. International Archive of Allergy and Immunology 48, 203-210.

Meydani SN, Lichtenstein AH, Cornwall S, Meydani M, Goldin B, Rasmussen H, Dinarello CA \& Schäfer E (1993) Immunologic effects of national cholesterol education panel step-2 diets with and without fish-derived $\omega-3$ fatty acid enrichment. Journal of Clinical Investigation 99, 105-113.

Parillo JE \& Fauci AS (1978) Mechanisms of corticosteroid action on lymphocyte subpopulation. III Differential effects of dexamethasone administration on subpopulations of effector cells mediating cellular cytotoxicity in man. Clinical and Experimental Immunology 31, 116-125.

Peter K, Unertl K \& Wroblewski H (1986) Wertung der Risikofaktoren und präoperative Untersuchungsprogramme. Anaesthesiologie und Intensivtherapeutische Notfallmedizin 181, 45-56.

Ryhänen P, Huttunen K \& Ilonen J (1984) Natural killer cell activity after open-heart surgery. Acta Anaesthesiologica Scandinavica 28, 490-492.

Sanders TAB \& Roshanai F (1983) The influence of different types of $\omega-3$ fatty acids on blood lipids and platelet function in healthy volunteers. Clinical Science 64, 89-91.

Sanders TAB (1985) Influcence of fish oil supplements on man. Proceedings of the Nutrition Society of England and Scotland 44, 391-397.

Schmitz JE (1999) Intensivmedizin und Ernährung. In Ernährungsmedizin. Prävention und Therapie, pp. 465-477 [P Schauder and G Ollenschläger, editors]. Munchen: Urban und Fischer, Hrsg.

Schröder MT, Schäfer G \& Schauder P (1990) Characterization of glutamine transport into resting and concanavalin A-stimulated peripheral human lymphocytes. Journal of Cellular Physiology 154, $155-161$.

Sedman PC, Somers SS, Ramsden CW, Brennan TG \& Guillou PJ (1991) Effect of different lipid emulsions on lymphocyte function during total parenteral nutrition. British Journal of Surgery 78, 1396-1399.

Slade MS, Simmons RL, Yunis E \& Greenberg LJ (1975) Immunodepression after major surgery in normal patients. Surgery 78, 363-372.

Spieker-Polet H \& Polet H (1981) Requirement of a combination of a saturated and an unsaturated free faty acid and a fatty acid carrier protein for in vitro growth of lymphocytes. Journal of Immunology 126, 949-954.

Spey CJF (1972) Inhibition of lymphocytes recirculation by stress and corticotropin. Cellular Immunology 4, 86-92.

Tizard I \& Sheppard J (1982) Influence of palmitic acid on mouse 
lymphocyte function in vivo and in vitro. International Archives of Allergy and Applied Immunology 67, 197-199.

Tönnesen E \& Wahlgreen C (1988) Influence of extradural and general anaesthesia on natural killer cell activity and lymphocyte subpopulations in patients undergoing hysterectomy. British Journal of Anaesthesia 60, 500-507.

Tönnesen E, Mickley H \& Grunnet N (1993) Natural killer cell activity during premedication, anaesthesia and surgery. Acta Anaesthesiologica Scandinavica 27, 238-241.

Tönnesen E, Hüttel MS, Christensen NJ \& Schmitz O (1984) Natural killer cell activity in patients undergoing upper abdominal surgery: relationship to the endocrine stress response. Acta Anaesthesiologica Scandinavica 28, 654-660.
Tönnesen E, Brinklov MM, Christensen NJ, Olesen AS \& Madsen T (1987) Natural killer cell activity and lymphocyte function during and after coronary artery bypass grafting in relation to the endocrine stress response. Anaesthesiology 67, 526-533.

Virella G, Fourspring K, Hyman B, Haskill-Stroud R, Long L, Virella I, LaVia M, Gross AJ \& Lopes-Virella M (1991) Immunosuppressive effects of fish oil in normal human volunteers: correlation with in vitro effects of eicosapentanoic acid in human lymphocytes. Clinical Immunology and Immunopathology 61, 161-176.

Walton B (1979) Effects of anaesthesia and surgery on immune status. British Journal of Anaesthesia 51, 37-43. 